\title{
Hematological and Biochemical Profile of Spider Monkey (Ateles geoffroyi Kuhl) in Captivity
}

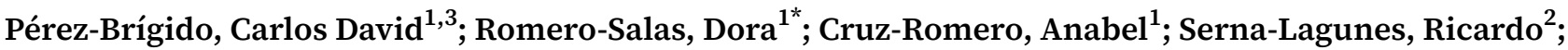 \\ Bravo-Ramos, José Luis ${ }^{1}$; Sánchez-Montes, Sokani ${ }^{3}$; Esparza-González, Sandra Cecilia ${ }^{4}$; \\ Anabel Elisa Rodríguez ${ }^{5}$
}

Citation: Pérez-Brígido, Carlos D., Romero-Salas, Dora, Cruz-Romero, Anabel, Serna-Lagunes, Ricardo, BravoRamos, José Luis, Sánchez-Montes, Sokani, Esparza-González, Sandra Cecilia, \& Rodríguez, Anabel E. (2021). Hematological and Biochemical Profile of Spider Monkey (Ateles geoffroyi Kuhl) in Captivity. Agro Productividad, 14(\#). https://doi.org/10.32854/agrop.v14i6.1974

Editor in Chief: Dr. Jorge Cadena Iñiguez

Estimated publication date: July 2021

This work is licensed under a Creative Commons Attribution-NonCommercial 4.0 International license
${ }^{1}$ Universidad Veracruzana. Facultad de Medicina Veterinaria y Zootecnia. Laboratorio de Parasitología. Unidad de Diagnóstico. Rancho Torreón del Molino. Carretera Federal Veracruz-Xalapa km 14.5, Col. Valente Diaz, Veracruz, Veracruz, México. C. P. 91697.

${ }^{2}$ Universidad Veracruzana. Facultad de Ciencias Biológicas y Agropecuarias Región Córdoba-Orizaba. Laboratorio de Bioinformática y Bioestadística. Calle Josefa Ortiz de Domínguez s/n Col. Centro, Peñuela, Amatlán de Los Reyes, Veracruz, México. C. P. 94945.

${ }^{3}$ Universidad Veracruzana. Facultad de Ciencias Biológicas y Agropecuarias Región Tuxpan. Carretera Tuxpan-Tampico km 7.5, Tuxpan, Veracruz, México. C. P. 92870.

${ }^{4}$ Universidad Autónoma de Coahuila. Facultad de Odontología Unidad Saltillo. Maestría en Ciencias Odontológicas. Blvd. Venustiano Carranza S/N, Col. República Oriente, Saltillo, Coahuila, México. C. P. 25280. 5Instituto de Patobiología Veterinaria (IPVET). Instituto Nacional de Tecnología Agropecuaria (INTA)-Consejo Nacional de Investigaciones Científicas y Técnicas (CONICET), Buenos Aires, Argentina.

*Corresponding author: dromero@uv.mx

\begin{abstract}
Objective: To estimate the hematological and biochemical reference values in Ateles geoffroyi individuals in captivity.

Design/Methodology/Approach: Eleven males and 23 females were captured and blood was collected from the coccygeal vein; conventional techniques were used to analyze the samples.

Results: Mean corpuscular volume (MCV; P<0.03) and platelets (PLT; P <0.04) were significantly higher in females than in males. In relation to biochemical blood values, the difference was not significant in male and female groups.

Study Limitations/Implications: Hematological and biochemical reference values of $A$. geoffroyi are within normal health parameters; they are between the ranges reported for other species of Neotropical primates and can be used as a reference in the health management of this species in captivity

Findings/Conclusions: Hematological and biochemical parameters of captive specimens of $A$. geoffroyi are described, which provide reference indicators for the health management of the species.
\end{abstract}

Keywords: reference values, Neotropical primates, blood chemistry, hematology.

\section{INTRODUCTION}

Anthropogenic activities impact the habitat of populations of wild primates, as is the case of the spider monkey (Ateles geoffroyi). This species inhabits from the southeast of Mexico to the northwest of Colombia (Di Fiore et al., 2008), and it fulfills an important role in the ecosystems as disperser of tropical forest tree seeds, and as prey of top predators (Chaves et al., 2011).

Arroyo-Rodríguez and Mandujano (2006) mention that when the habitat is fragmented, the species of primates can reduce their ability to move in the habitat to obtain quality foods, which has an impact on physiological alterations at the hematological and biochemical levels. In this sense, it is possible that A. geoffroyi is under risk of extinction according to the Red List of Threatened Species because the 
ecological characteristics required by the species for their diet are so sensitive that due to the fragmentation of their habitat their populations have reduced in size (Cuarón et al., 2008), and they possibly present changes in their hematological and biochemical profiles, so it is important to study and record their parameters to generate preventive health measures.

A way to generate information about the hematological and biochemical parameters is to evaluate the individuals of $A$. geoffroyi in captivity in zoos and other captivity models in Mexico, since in absence of local reference values for wild populations of $A$. geoffroyi or in captivity, reference values of another species of the same genus are used (Ríos, 2015; Zambrano, 2016). For this reason, the objective of the study was to describe the reference values for the hematological and biochemical profiles of adult males and females of A. geoffroyi under conditions of captivity. The parameters generated in the study can be considered as reference values to determine the health status of this species in captivity and as reference of the physiological functions in the wild primate populations and those in captivity.

\section{MATERIALS AND METHODS}

Specimens studied and biological material collection: During the years 2018 to 2019, 15 specimens of A. geoffroyi were captured in the zoo, Parque Zoológico y Jardin Botánico Miguel Ángel de Quevedo (ZOOMAQ), registered as Property and Facility for Wild Life Management (Predio e Instalación para el Manejo de Vida Silvestre, PIMVS) and located in the city of Veracruz, Veracruz. Another 19 specimens of A. geoffroyi (9 monkeys from the Pipiapan locality and 10 from the locality of Tanaxpi) were studied in the Management Unit for Wild Life Conservation (Unidad de Manejo para la Conservación de la Vida Silvestre, UMA) "Hilda Ávila de O’Farril”, a unit devoted to the research of primates. This UMA is located in the Catemaco-Coyame highway, municipality of Catemaco,

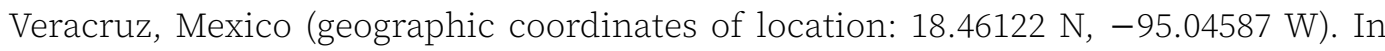
total, both from the ZOOMAQ and the UMA, 11 males and 23 females of A. geoffroyi were captured in captivity. The monkeys were anesthetized with darts with syringes of $3 \mathrm{~mL}$ with a dose of $5 \mathrm{mg} \mathrm{kg}^{-1}$ of ketamine chlorhydrate (Ketanil ${ }^{\circledR}$, Wildlife Pharmaceuticals, Windsor, USA), loaded in a $\mathrm{CO}_{2}$ rifle (JM Standard ${ }^{\circledR}$, Daninjet, Børkop, Denmark).

From each specimen, $4 \mathrm{~mL}$ of blood tissue were obtained from the coccygeal vein and placed in tubes with ethylenediaminetetraacetic acid (EDTA) and the rest of the sample was placed in serum separating tubes. All the samples were conserved at $4{ }^{\circ} \mathrm{C}$ and $6 \mathrm{~h}$ after the harvest they were processed. The animals captured were subjected to a complete physical exam and each was weighed, and then the specimen was placed in a cage until complete recovery from anesthesia.

Hematic cytometry: The total recount of erythrocytes (red blood cells - RBC) was carried out, and packaged cells volume (PCV), hemoglobin (Hb), leukocytes (white blood cells - WBC), and platelets (PLT) were estimated; RBC indexes: mean corpuscular volume (MCV), mean corpuscular hemoglobin $(\mathrm{MCH})$, and mean corpuscular hemoglobin concentration (MCHC). Blood smears stained with fast hemocolor were 
carried out (Diff-Quick ${ }^{\mathrm{TM}}$, Hycel, Mexico), where 100 cells were counted in each of them for the differential recount of leukocytes. This information was generated with a complete hemogram in an $\mathrm{MD}-8^{\circledR}$ automatic analyzer (Beckman Coulter, California, USA).

Blood chemistry: The concentration of glucose, ureic nitrogen in blood, urea, total protein, albumin, globulin, albumin/globulin rate, creatinine, cholesterol, triglycerides, alkaline phosphatase, calcium and iron. These parameters were quantified with a chemical analyzer ARCHITECT ${ }^{\circledR}$ ci16200, Abbott Core Laboratory (Abbott, Abbott Park, Illinois, USA).

Data analysis: The values obtained from the erythrocyte parameters and blood chemistry were described through descriptive statistics by group (Zoo vs UMA) and by sex (females vs males) of the primates sampled. These parameters were compared through the Kolmogorov-Smirnov test that compares the median and the ranges at 95\% of reliability between group of primates (Zoo vs UMA) and by sex (females vs males); the comparison included 10000 bootstrap resamples as a method to evaluate the reference ranges at 95\% of reliability; the inferior reference limit was defined at 2.5\% percentile and the superior limit at $97.5 \%$ percentile; to determine whether there were differences between the values of the groups studied, the Mann-Whitney's $U$ test at $\mathrm{P}<0.05$ was applied. The analyses were carried out with the SPSS V. 19 software.

\section{RESULTS AND DISCUSSION}

The average weight of females was $5.5 \pm 0.6 \mathrm{~kg}$ and the size $65-70 \mathrm{~cm}$, while the males had $6.0 \pm 1.3 \mathrm{~kg}$ of average weight and a size of $80-90 \mathrm{~cm}$. The hematological and biochemical values analyzed in males and females are presented in Table 1 and 2 . The MCV $(\mathrm{P}<0.03)$ and PLT $(\mathrm{P}<0.04)$ were significantly higher in females than in males, without significant differences between the hematological and biochemical values. The values of platelets $(p=0.018)$, neutrophils $(p=0.021)$, eosinophils $(p=0.002)$, basophils $(p=0.009)$, lymphocytes $(p=0.006)$ and monocytes $(p=0.042)$ were significantly different (Table 3), which is associated to the type of management of the monkey population (Zoo vs UMA), such as exposure to different infectious agents, diet, weight, age and characteristics of captivity (Chen et al., 2002; Xie et al., 2013).

The hematological values provided important data about the health of the monkeys studied such as the analytes, which are biomarkers of the possible presence of a disease. On the other hand, this report of reference values for A. geoffroyi constitutes basic information to be contrasted with other populations of the species in captivity and to determine their health status (Ríos, 2015; Zambrano, 2016).

Most of the hematological indexes obtained in this study were similar to those reported by Ríos (2006) in A. chamek and they are within the parameters proposed by International Species Information System (ISIS, Calle and Joslin, 2015), but they were lower than those reported in A. fusciceps (Zambrano 2016); the red blood cell count was higher in this study, and it can be conditioned to the altitude where the monkeys are in captivity, as index of lower oxygen pressure (Castañeda et al., 2013). 


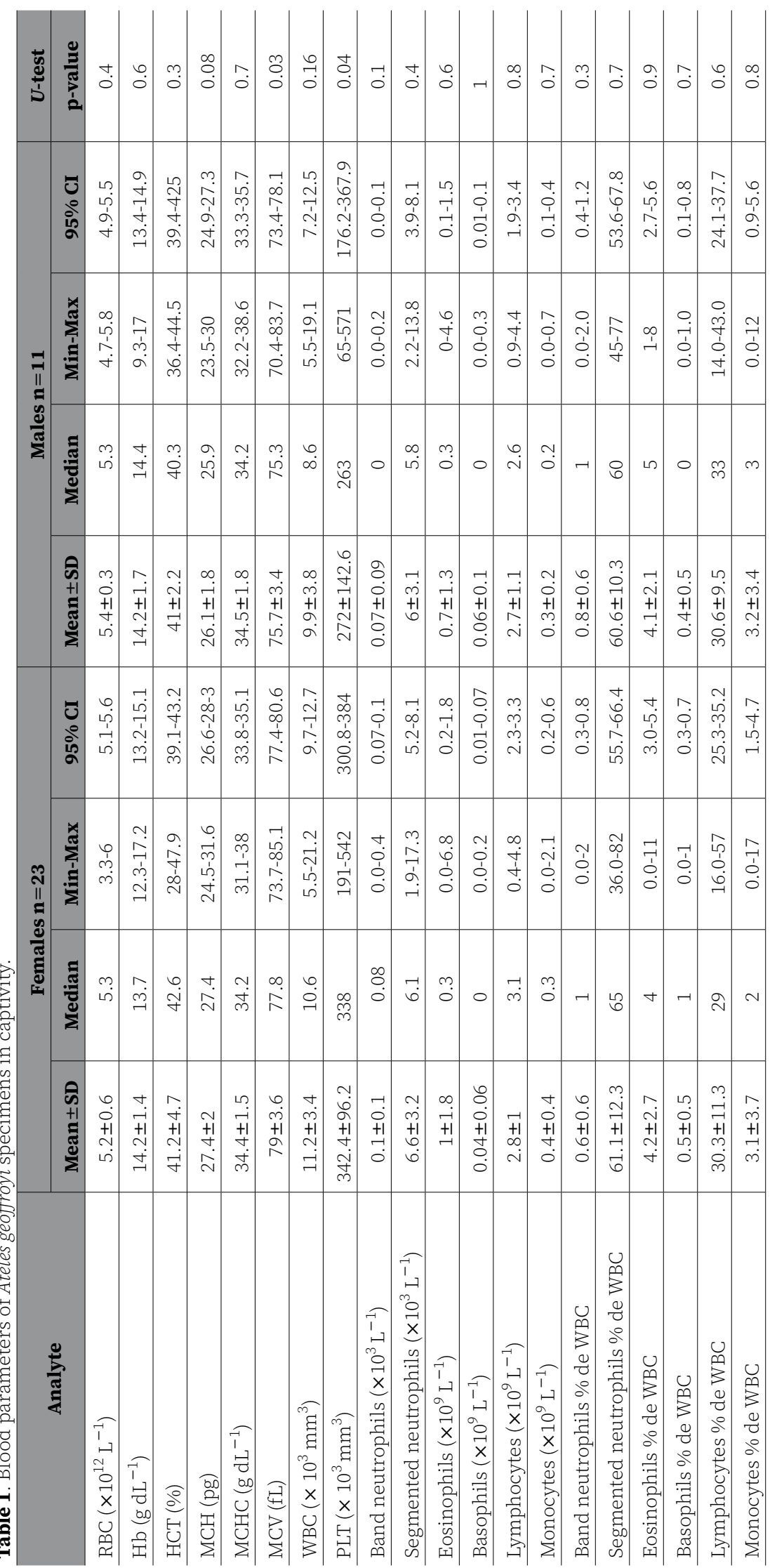




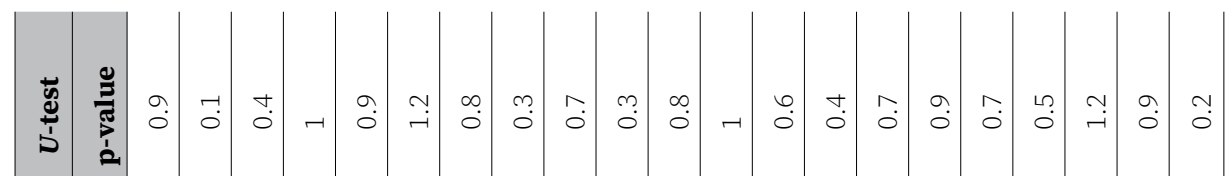

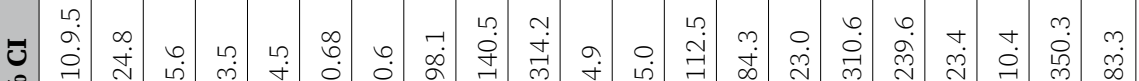

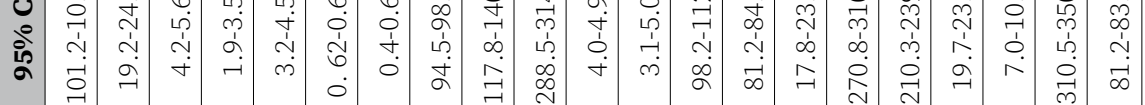

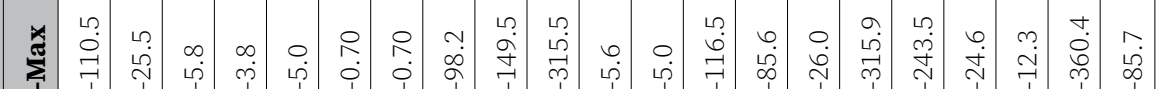

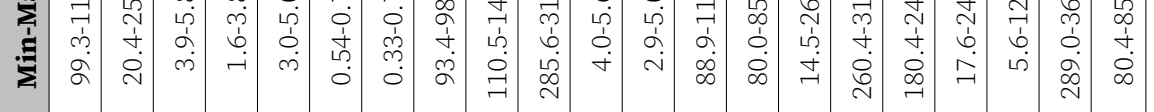

恶

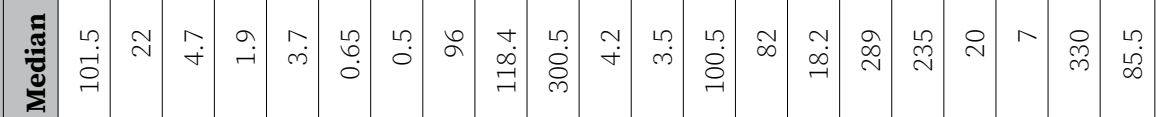

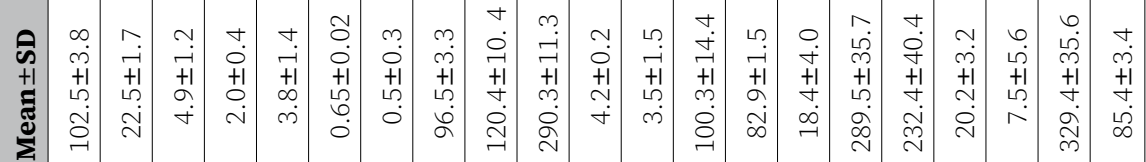

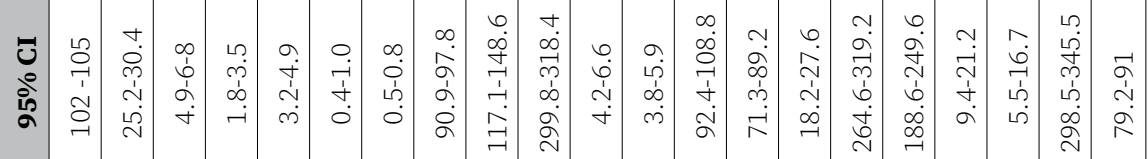

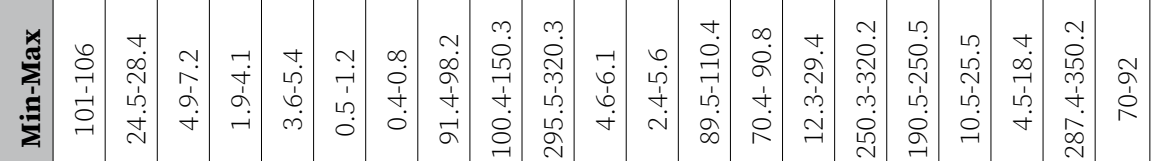

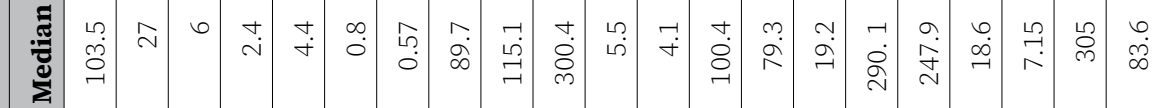

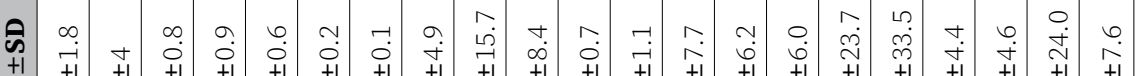

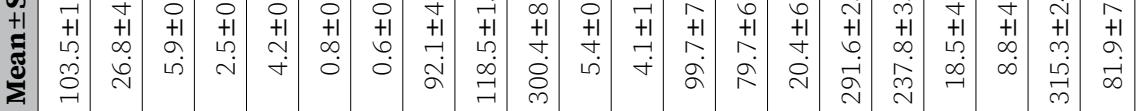

7

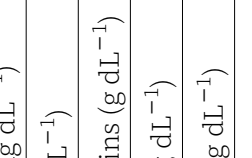

焉

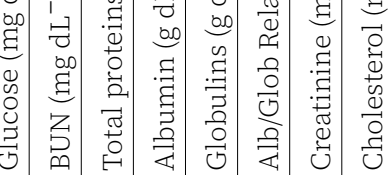


Table 3. Comparison of hematological values of A. geoffroyi in captivity.

\begin{tabular}{l|c|c|c|c}
\multirow{2}{*}{ Hematological values } & \multicolumn{2}{|c|}{ UMA Hilda } & ZOOMAQ & \multirow{2}{*}{$\mathbf{p}$} \\
\cline { 2 - 4 } & Pipiapan n=9 & Tanaxpi n=10 & $\mathbf{n = 1 5}$ & \\
\hline $\mathrm{RBC}\left(\times 10^{12} \mathrm{~L}^{1}\right)$ & $5.0 \pm 0.91$ & $5.28 \pm 0.44$ & $5.45 \pm 0.36$ & 0.550 \\
\hline $\mathrm{Hb}(\mathrm{g} \mathrm{dL})^{1}$ & $13.4 \pm 2.07$ & $15.14 \pm 1.50$ & $14.09 \pm 1.18$ & 0.137 \\
\hline $\mathrm{HCT}(\%)$ & $39.4 \pm 5.53$ & $42.3 \pm 3.3$ & $41.44 \pm 3.3$ & 0.344 \\
\hline $\mathrm{WBC}\left(\mathrm{x} 10^{3} \mathrm{~mm}^{3}\right)$ & $11.14 \pm 3.7$ & $11.3 \pm 3.0$ & $10.22 \pm 4.0$ & 0.403 \\
\hline $\mathrm{PLT}\left(\mathrm{x} 10^{3} \mathrm{~mm}^{3}\right)$ & $400 \pm 101$ & $319 \pm 68.47$ & $271.9 \pm 127.5$ & 0.018 \\
\hline Segmented neutrophils & $52 \pm 12.78$ & $67.6 \pm 5.42$ & $61.93 \pm 10.97$ & 0.021 \\
\hline Eosinophils \% de WBC & $6.33 \pm 2.54$ & $4.8 \pm 2.29$ & $2.6 \pm 1.63$ & 0.002 \\
\hline Basophils \% de WBC & $0.22 \pm 0.44$ & $0.9 \pm 0.316$ & $0.4 \pm 0.5$ & 0.009 \\
\hline Lymphocytes \% de WBC & $39.7 \pm 11.62$ & $23.7 \pm 6.41$ & $29.33 \pm 8.7$ & 0.006 \\
\hline Monocytes \% de WBC & $1.22 \pm 0.97$ & $2.3 \pm 1.05$ & $5.0 \pm 4.73$ & 0.042 \\
\hline
\end{tabular}

The red blood cells found in this study when comparing them to other non-human primates, indicate a balance of erythropoiesis and destruction of erythrocytes (Ihrig et al., 2001; Yu et al., 2019; Yeo et al., 2019). The hematocrit (HCT) was found to be higher in the monkeys studied, which indicates a state of balance in terms of the water balance regulator mechanism (Armstrong and Johnson, 2018), while the recount of white blood cells (WBC) was found within the normal parameters (García-Feria et al., 2017) and the recount of platelets was similar in comparison to other values in primates (Ferreira et al., 2018). However, the increase of eosinophils found is attributed to helminthic infections in the monkeys studied (Rahimi and Khanaliha, 2018).

In this study there was no evidence of any effect from the sex (male vs female) on the biochemical parameters of the monkeys studied, effect that has also not been reported in other studies of Neotropical primates (Rovirosa-Hernández et al., 2012; Canales-Espinosa et al., 2015; García-Feria et al., 2017).

In this study, the males had significantly higher weight and size than the females, resulting from their sexual dimorphism (de Thosy et al., 2001), but with similar concentrations of creatinine, as a result of a similar diet, since the dietetic intake and the muscular mass promote similarities in the content of creatinine (Kaneko, 1989). The levels of cholesterol, triglycerides, HDL and LDL of the monkeys studied suggest that they have an intake rich in proteins, while the transaminases, alanine aminotransferase (ALT), aspartate aminotransferase (AST), and blood ureic nitrogen (BUN) suggest a normal hepatic function (Rovirosa-Hernández et al., 2012; CanalesEspinosa et al., 2015; García-Feria et al., 2017).

\section{CONCLUSIONS}

This study describes the hematological and biochemical parameters of specimens in captivity of A. geoffroyi, with reference values that provide indicators for the health management of this species in captivity. 


\section{AKNOWLEDGEMENTS}

We thank the Zoo and Botanical Park (PIMVS) "Miguel Ángel de Quevedo (INE/CITES/DGVS-ZOO-E0042-01-VER), and the Management Unit for the Conservation of Wild Life (UMA) "Hilda Ávila de O’Farril”, municipality of Catemaco, Veracruz, Mexico, for the facilities for sample collection of the monkeys, as well as the staff from the Parasitology Laboratory of the Veterinary Medicine and Animal Science School of Universidad Veracruzana and the undergraduate students for their support in this study.

\section{Compliance with ethical standards}

This project was approved by the Bioethical and Animal Welfare Commission of the Veterinary Medicine and Animal Science School of the Universidad Veracruzana.

\section{REFERENCES}

Armstrong, L.E., Johnson, E.C. (2018). Water intake, water balance, and the elusive daily water requirement. Nutrients, $10: 1928$. Arroyo-Rodríguez, V., Mandujano, S. (2006). Forest Fragmentation Modifies Habitat Quality for Alouatta palliata. Int J Primatol 27:1079-1096.

Calle, P., Joslin O. (2015). New World and Old World Monkeys. Pp. 309-310. In: Zoo and Wild Animal Medicine. Miller, R. \& Fowler, M. (Eds). Vol. 8. St. Louis, Missouri: Elsiever.

Canales-Espinosa, D., de Jesús Rovirosa-Hernández, M., de Thoisy, B., Caba, M., \& García-Orduña, F. (2015). Hematology and serum biochemistry in wild howler monkeys. In: Howler Monkeys Adaptative Radiation, Systematics and Morphology (Ed. Kowalewski MM, Garber PA, Cortés-Ortíz L, Urbani B, Youlatos D). Springer, New York, NY. Pp. 179-202.

Castañeda, F., Buriticá E., \& Orjuela, D. (2013). Evaluación de los parámetros hematológicos del tití gris (Saguinus leucopus Günther 1876) en cautiverio y su relación con la edad y el sexo. RECIA 6:51-58.

Chaves, Ó.M., Stoner, K.E., Arroyo-Rodríguez, V., \& Estrada, A. (2011). Effectiveness of spider monkeys (Ateles geoffroyi vellerosus) as seed dispersers in continuous and fragmented rain forests in southern Mexico. Int J Primatol 32:177-192.

Chen, Y., Ono, F., Yoshida, T., \& Yoshikawa, Y. (2002). Relationship between body weight and hematological and serum biochemical parameters in female Cynomolgus monkeys (Macaca fascicularis). Experimental Animals 51:125-131.

Cuarón, A., Morales, A., Shedden, A., Rodríguez-Luna, E., de Grammont, P., \& Cortés-Ortiz, L. (2008). Ateles geoffroyi. The IUCN Red List of Threatened Species 2008: e.T2279A9387270.

Di Fiore, A., Link, A. \& Dew, J.L. (2008). Diets of wild spider monkeys. Pp. 81-137. In: Spider Monkeys: Behavior, Ecology and Evolution of the Genus Ateles. Campbell, C.J. (Ed). Cambridge University Press, Cambridge. UK.

Ferreira, A.F., Queiroga, F.L., Mota, R.A., Rêgo, E.W., Mota, S.M., Teixeira, M.G., \& Colaço, A. (2018). Hematological profile of captive bearded capuchin monkeys (Sapajus libidinosus) from Northeastern Brazil. Cienc Rural 48: e20180065

García-Feria, L.M., Chapman, C.A., Pastor-Nieto, R., \& Serio-Silva, J.C. (2017). Biochemical and hematological evaluations of black howler monkeys (Alouatta pigra) in highly degraded landscapes in Mexico. J Med Primatol 46: 304-310.

Xie, L., Xu, F., Liu, S., Ji, Y., Zhou, Q., Wu, Q., Gong, W., Cheng, K., Li, J., Li, L., Fang, L., Zhou, L., \& Xie, P. (2013). Age- and sexbased hematological and biochemical parameters for Macaca fascicularis. PloS One 8: e64892.

Yu, W., Hao, X., Yang, F., Ma, J., Zhao, Y., Li, Y., Wang, J., Xu, H., Chen L., Liu, Q., Duan, S., Yang Y., Huang F., \& He, Z. (2019). Hematological and biochemical parameters for Chinese rhesus macaque. PloS One 14:e0222338. 